\title{
Rating of Sound Absorption for EFBMF Acoustic Panels according to ISO 11654:1997
}

\author{
Emedya Murniwaty Samsudin ${ }^{1 *}$, Lokman Hakim Ismail ${ }^{1}$, Aeslina Abd Kadir ${ }^{1}$, Ida Norfaslia Nasidi $^{1}$ and Noor \\ Sahidah Samsudin ${ }^{2}$ \\ ${ }^{1}$ Faculty of Civil and Environmental Engineering, UTHM, Johor \\ ${ }^{2}$ Faculty of Architecture, Planning and Surveying UiTM, Seri Iskandar, Perak
}

\begin{abstract}
Empty fruit bunch fibre (EFB) and mesocarp fibre (MF) have been used in the fabrication of a new acoustic panel as a sound absorber for building. Measurements were carried out following ISO 354 in the mini reverberation chamber and the sound absorption performance of EFBMF acoustic panels were rated based on ISO 11654. Measurements of the new EFBMF acoustic panel involves five panel designs of 100 EFB dust panels, 80:20 dust panels, 100MF coir panels, 90:10 coir panels and 50:50 coir panels with $5 \mathrm{~cm}$ of initial thickness. Results showed that $100 \mathrm{MF}$ coir panel achieved $\alpha_{\mathrm{w}}$ of 0.90 coefficient and was rated as Class A absorber followed by 90:10 coir panels with $\alpha_{w}$ of 0.85 coefficient and 100 EFB dust, 80:20 dust and 50:50 coir panels having $\alpha_{w}$ of 0.80 coefficients and been rated as Class B absorber. This research has successfully defined that EFB and MF are viable to be used as raw fibre for acoustic absorber for building.
\end{abstract}

\section{Introduction}

In the acoustic measurement for sound absorption of a building material, reverberation room method or ISO 354 [1] is often used. Even though an absorption coefficient of any material could be obtained from the normal wave incidence testing, but in many practical applications the random incidence testing is desired [2]. Random incidence test method requires materials to be tested in a reverberation chamber to specify the sound absorption performance.

Reverberation room method utilized Sabine's formula as shown by Equation 1 to define the sound absorption coefficient value $\left(\alpha_{s}\right)$ of a material at specific one-third-octave band of frequency. The range of frequencies for reverberation room testing was in between $100 \mathrm{~Hz}$ to $5000 \mathrm{~Hz}$ as been specified in the ISO 266: 1997 [3].

$$
x=\frac{0.20 \mathrm{~V}}{i}\left(\frac{1}{\mathrm{r} s}-\frac{1}{\mathrm{i} s}\right)
$$

In the Sabine's formula, $V$ represent the closed volume of test chamber, $S$ is the total absorbing area and $T s$ and $T e$ represent the reverberation time inside an occupied chamber and empty chamber respectively. Theoretically, reverberation time is defined as the time required by the sound pressure level to decay by $60 \mathrm{~dB}$ after the sound source has stopped with $\mathrm{RT}_{60}$ or $\mathrm{T}_{60}$ symbol normally been used to represent the value.

Rating of sound absorption for building material is done reffering to $\alpha_{s}$ value at mid-band frequencies of $250 \mathrm{~Hz}, 500 \mathrm{~Hz}, 1000 \mathrm{~Hz}, 2000 \mathrm{~Hz}$ and $4000 \mathrm{~Hz}$. According to ISO 11654: 2007 [4], sound absorption material are rated to be either Class A, B, C, $\mathrm{D}, \mathrm{E}$ or not classified based on the single-number weighted sound absorption coefficient $\left(\alpha_{w}\right)$ value. Materials having absorption coefficient value more than 0.5 are considered as a good absorber while materials having $\alpha_{s}=0.2$ or less are a reflective for acoustic application [5].

\subsection{Utilization of palm oil wastes as sound absorber}

\subsubsection{Palm oil wastes in Malaysia}

Oil palm planted in Malaysia is from Elaeis guineensis species and was first found in West Africa. Resulting from British Industrial Revolution, oil palm plantation was later expanded and commercially planted in South East Asia especially in Malaysia and Indonesia. Oil palm was first introduced to Malaysia in 1870 by British colony and the first commercial oil palm plantation in Malaysia was set up in year 1917 in Tennamaran Estate, Selangor [6]. The first Malaya company actively planted palm oil in Malaysia is Guthrie and Co. during 1924 in Kluang, Johor. Oil palm industry in Malaysia keeps on growing each year with the growth of world population and vast economic development by most countries importing oil for food. Palm is edible oil product that becomes one of the most important dietary components and source of fats worldwide. The demand for oil palm is also increase tremendously with the increasing of world population each year [7] and [8].

\footnotetext{
*Corresponding author: emedya@uth,m.edu.my
} 
Oil palm production produced plenty of biomass which includes wastes from oil palm trunks (OPT), oil palm frond (OPF), empty fruit bunches (EFB), palm pressed fibres (PPF), palm kernel shells (PKS) and palm oil mill effluent (POME) [6] and [9]. The presence of huge amount of accumulated wastes resulting from the oil palm processing activites has created major waste disposal problems to the country. Among those wastes, EFB and MF are the larger lignocellulose biomass been produced [6] followed by MF and PKS [9]. Hence, government needs to allocate more money and assign more hectares of land to dispose those wastes. Moreover, accumulated palm oil wastes in the landfill could also cause another environmental issues if not been reused [10].

\subsubsection{Sound absorption performance of palm oil fibres}

The most recent local research utilizing palm oil fibers as sound absorption materials were done by [11],[12], [13] and [14].

Research by [11] used oil palm empty fruit bunches in different masses and thicknesses to create samples with different densities value. This research has found that higher density samples able to improve the sound absorption performance at high frequency region while air gap is necessary to improved absorption performance at low frequency region. Moreover, for $50 \mathrm{~mm}$ thick OPEFB sample having $292 \mathrm{~kg} / \mathrm{m}^{3}$ of density could achieve SAC value of 0.90 in average at frequency above than $1000 \mathrm{~Hz}$.

In [12], different weight percentage of oil palm mesocarp fiber was mixed with different percentage of polyurethane (PU). Impedance tube measurement following ASTM E1050-09 was used as the guidance to obtain the sound absorption coefficient for $50 \mathrm{~mm}$ thick samples at low and high frequency regions. This research has concludes that sample containing $90 \%$ of mesocarp and $10 \%$ of PU achieved the highest NRC value of 0.66 compared to the others. Besides, this research also evidences that when PU content increased, density of sample will increase but lowering its porosity. This will result in lower sound absorption capability.

Earlier, [13] also utilizing mesocarp fiber and PU in their research for samples having different thicknesses. In this research the mix ratio is $70 \% \mathrm{MF}$ : $30 \%$ PU with thickness ranging from $10 \mathrm{~mm}$ to $40 \mathrm{~mm}$ thick. However, $5 \mathrm{~mm}$ and $10 \mathrm{~mm}$ of air gap were incorporated at the back of the sample during conducting the impedance tube testing. Findings show that thick samples having $30 \mathrm{~mm}$ and $40 \mathrm{~mm}$ thickness are good at medium and low frequency region. It was also found that by incorporating an air gap to the back of the test samples able to improve absorption performance of thin samples at most of the frequencies but showing less effect for thicker samples.

Finally research by [14] compares on the absorption performance of $30 \mathrm{~mm}$ and $50 \mathrm{~mm}$ thick oil palm EFB (OPEFB) with date palm fiber (DPF) using impedance tube following ISO 10534 and ASTM E1050 :98. Results shows that $50 \mathrm{~mm}$ OPEFB achieve its peak absorption of almost $90 \%$ absorption at higher frequency with considerably good performance at frequency 2000 Hz. However, when results were compared to DPF, OPEFB performed slightly lower at the most of the testing frequency.

Most of earlier research involving palm oil fibers as a new sound absorption material were done following either ISO 10534 or ASTM E 1050. Both methods used impedance tube as the measurement equipment with smaller sample size which is very suitable for material development besides low in cost. However, this method is only utilizing standing wave/direct wave incident which does not reflecting the actual performance of the samples in the real application. Therefore, it is necessary to conduct the same research using reverberation room method to acknowledge the samples performance as sound absorber in the real application.

\section{Methodology}

This research used raw EFB and MF collected from local oil palm plantation (Kulim Plantation (M) Sdn. Bhd) located in Kluang, Johor. EFBMF panels used in this classification were fabricated in five different panel mix designs consisted of 100 EFB dust panels, 80:20 dust panels, 100MF coir panels, 90:10 coir panels and 50:50 coir panels having $5 \mathrm{~cm}$ of initial thickness. Hot pressed compression method was used in the fabrication with urea formaldehyde (UF) as the wood binder for the panel.

Sound absorption testing was conducted in a mini reverberation chamber following ISO 354:2003 [1]. This testing measures the reverberation time $\left(\mathrm{RT}_{60}\right)$ using sound level meter type $01 \mathrm{~dB}$ connected to a symphonie analyzer and analyzed the sound absorption coefficient/Sabine's absorption coefficient $\left(\alpha_{\mathrm{s}}\right)$ values using dBBati32 software analyzer. Measurements of RT were done in four different microphone positions with turning position by $90^{\circ}$ in each set of measurement (refer Figure 1).

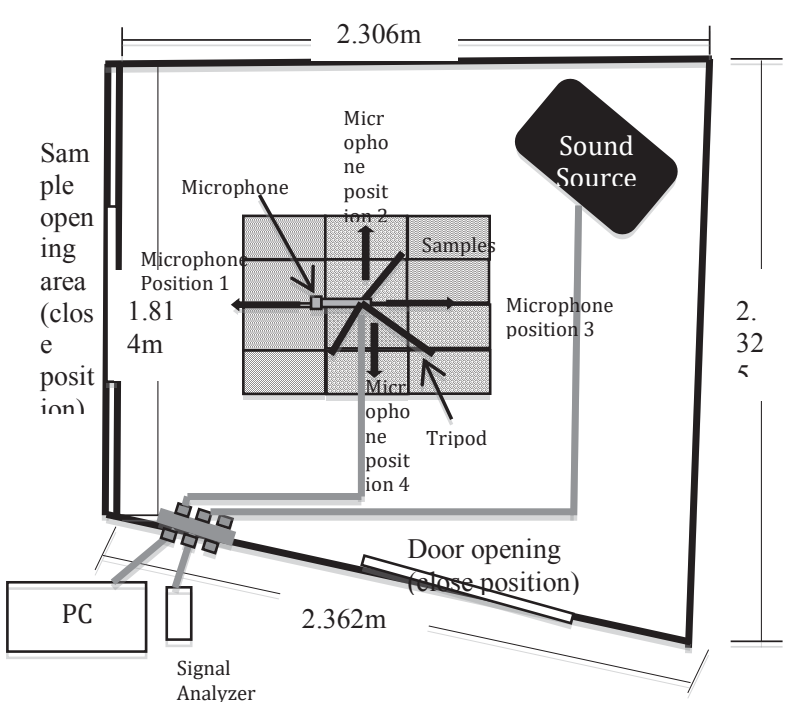

Fig. 1. Schemetic drawing and microphone positions 


\subsection{Pre-treatment and Panels fabrication}

Earlier before fabrication, the raw fibers were treated with $2 \%$ of $\mathrm{NaOH}$ to eliminates any impurities and excessive oil attached on the fibers. Research by [15] revealed that pretreatment using $2 \% \mathrm{NaOH}$ solutions is more effective than hot water treatment in removing oil and the fiber will also remain in shape with less surface damages. Fibers were first been soaked with cold water for 24 hours and drained out to removed all dirt and unwanted particles. Afterward, the drained fibers were soaked again into water containing $2 \%$ of $\mathrm{NaOH}$ within 30 minutes and rinse off using clean-running water to eliminate the residue oil and excessive sodium content. Finally, the washed fibers were sun-dried for 2 to 3 days depending on weather conditions to reduce its moisture. The purpose of sun-drying the fiber is to reduce energy usage from electrical oven, which thus, could contributes to less carbon footprint from the heating process. However, to ensure that all fiber containing less than $10 \%$ of moisture before been used for fabrication, approximately 15 to 30 minutes of oven-dried using $110^{\circ} \mathrm{C} \pm 5^{\circ} \mathrm{C}$ is needed.

Next, EFB and MF were shredded and grinded using specific machine in the laboratory before sprayed with the UF. This research used $15 \%$ of UF liquid resin added with $1 \%$ of $\mathrm{NH}_{4} \mathrm{Cl}$ as the hardener to fasten the hardening process of the liquid binder. Hot pressing work was done using hot press machine in the Timber Fabrication Laboratory, UTHM. This machine needed to be heated up to $180^{\circ} \mathrm{C}$ before loading the wet mix fibers into. The temperature were maintained at $180{ }^{\circ} \mathrm{C}$ throughout the pressing time of 15 minutes using 1000 psi of pressing load. Finally, samples were removed from the machine and left to cold under room temperature before removing the mould.

\subsection{Reverberation room testing}

Reverberation room testing for this research was done in a downscale chamber (RT Mini Chamber) located at Faculty of Architecture, Planning and Surveying, University Technology MARA, Shah Alam. This chamber consisted of two interconnected chambers and was build to following BS EN ISO 140-1:1998. Mini chamber were designed to be use for measurement of small-scale sample sized $\pm 1 \mathrm{~m}^{2}$. It is a quadrangular chamber having total surface area of $\pm 30 \mathrm{~m}^{2}$ and total volume of $11.8 \mathrm{~m}^{3}$.

Figure 2 shows the arrangement for test samples, sound source and microphone in the mini chamber during testing. In this testing, 15 test panels sized 0.30 meter x 0.22 meter x 0.05 meter thick of each design mix were laid in array resting on the floor. Samples were placed at the centre of the test chamber with the perimeter surface area was completely sealed with a reflective material, leaving only the top surface of the panels exposed to recieve the sound incidence.

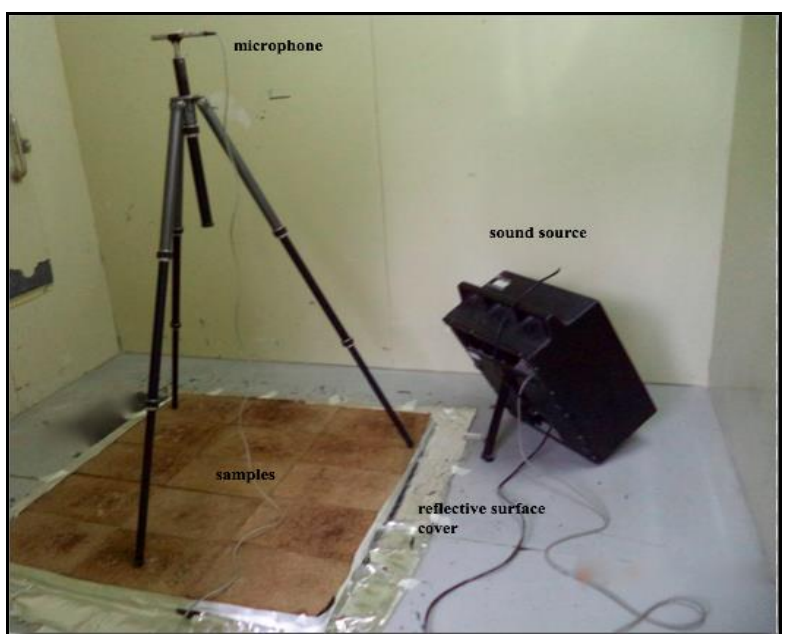

Fig. 2. Arrangement of panels and equipment in the test chamber.

Measurements of reverberation time were done in seconds (s), starting from measurement of an empty chamber followed by an occupied chamber containing EFBMF acoustic panels by mix design. Random pink noise was used in a full blast sound power of $100 \mathrm{~dB}$ inside the closed chamber. Since most of the surfaces inside the chamber are reflective, therefore, it will results in higher RT values when the sound signal stopped. When an absorbent placed into the chamber, the shorter RT will be obtained due to dissipation of sound energy that happen when the sound wave hits onto the absorptive surface.

\section{Results and discussion}

Theoretically, the shorter the reverberation time, means the more sound were absorbed and the gap between curve-lines representing the empty chamber with the occupied chamber will be distance. In this measurements, it was found that different panel design does not giving large effect to the reverberation time since the total absorbing surface area of those panels are almost the same. The longest reverberation time in the empty chamber was found at $2.08 \mathrm{~s}$ at frequency 1600 Hz. On average, reverberation time in the occupied chamber achieved less than $1.2 \mathrm{~s}$ in between frequency $400 \mathrm{~Hz}$ to $5000 \mathrm{~Hz}$. Since results for all panels designs shows alignment for all curve-lines laid very close to each other, therefore, it was predicted that performances of all panel mixes are almost similar to each other. Results for reverberation time of an empty chamber and occupied chamber is presented in Figure 3. 


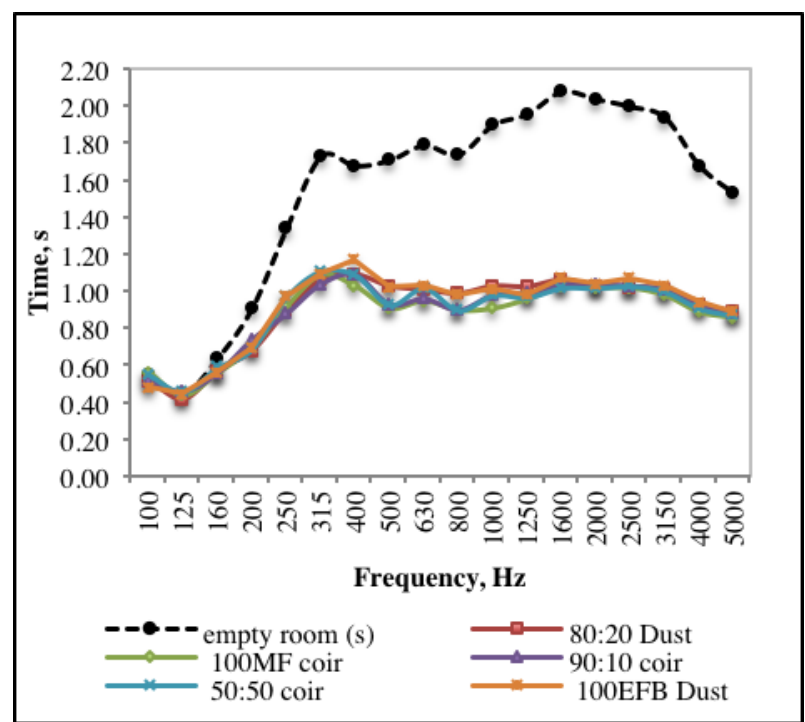

Fig. 3. Reverberation time for an empty chamber and chamber occupied with EFBMF acoustic panels

Sabine's absorption coefficient or represented as $\alpha_{s}$, relates between the ratio of room volume to the total absorbing surface area in a room. The decrease in $\mathrm{RT}_{60}$ inside the test chamber containing test samples indicates that the test material successfully absorbed the sound incident during testing. Figure 4 show the Sabine's absorption performance of EFBMF acoustic panels in the reverberation chamber. At below than frequency 300 $\mathrm{Hz}$, absorption performance of all samples are slightly unstable with all coir panels seems unable to give positive $\alpha_{\mathrm{s}}$ value especially at frequency $100 \mathrm{~Hz}$ and 125 Hz. This made the results for below than $200 \mathrm{~Hz}$ unreliable for this testing. However, results for below than $250 \mathrm{~Hz}$ did not influence in the sound absorber rating according to ISO 11654 [4]. Therefore, the results could be ignored.

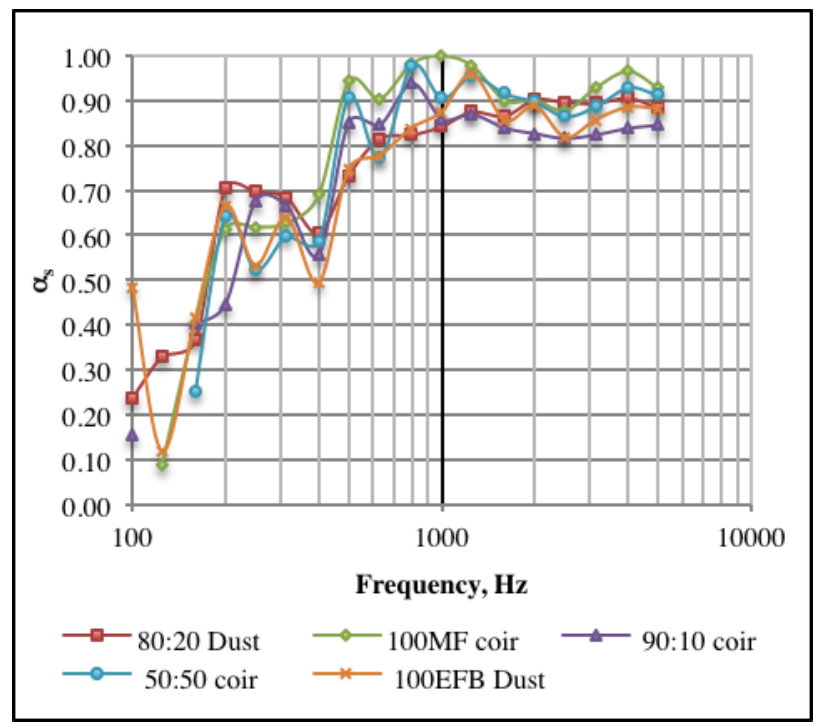

Fig. 4. Sound absorption performance of EFBMF acoustig panels in the reverberation chamber
In Figure 4, the highest $\alpha_{\mathrm{s}}$ value achieved by $100 \mathrm{Mf}$ coir panel at frequency $900 \mathrm{~Hz}$ to $1000 \mathrm{~Hz}$ which is near to 1.0 coefficient. Overall, $100 \mathrm{MF}$ coir panel also exhibits higher absorption coefficient value compared to the other panels throughout the testing frequencies. This provides an indicator that $100 \mathrm{MF}$ coir panel will have the highest rangking absorber according to the standard. Meanwhile, Figure 5 illustrates the rating curves for EFBMF panels according to ISO 11654:1997 [4], while Table 1 summarized the final results for all tested panels.

As been predicted earlier, $100 \mathrm{MF}$ coir panel owned the highest rank followed by 90:10 coir panel and the three other panels (50:50 coir, 100 EFB dust and 80:20 dust). The $\alpha_{\mathrm{pi}}$ values for $100 \mathrm{MF}$ coir panel are 0.70, $0.90,0.90,0.90$ and 0.80 at frequency $250 \mathrm{~Hz}, 500 \mathrm{~Hz}$, $1000 \mathrm{~Hz}, 2000 \mathrm{~Hz}$ and $4000 \mathrm{~Hz}$ respectively. The weight of sound absorption value for this panel achieved 0.90 coefficients, which is the highest among others.

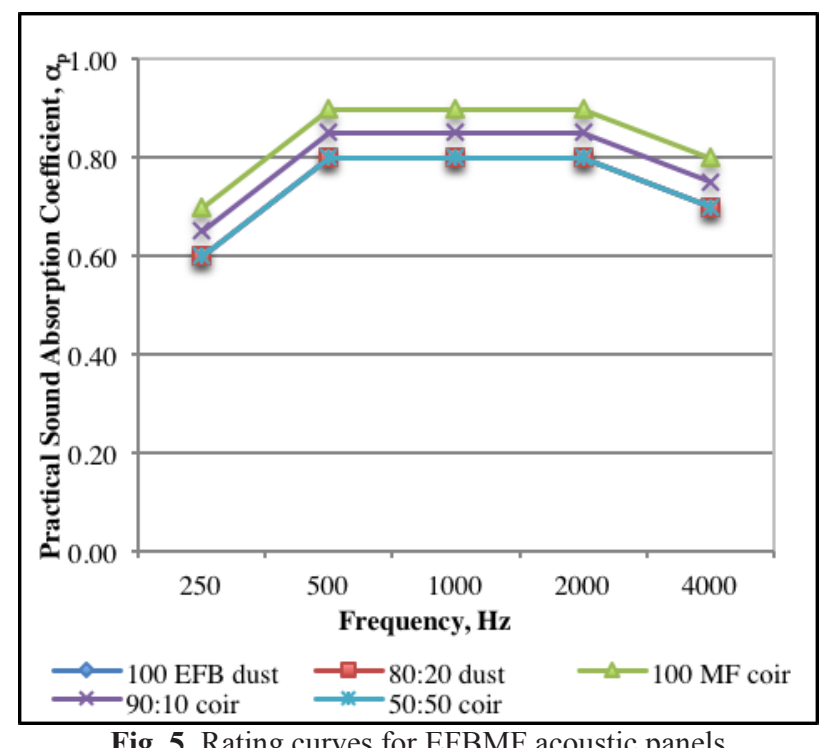

Fig. 5. Rating curves for EFBMF acoustic panels

As been summarized in the Figure 5, the $\alpha_{\mathrm{w}}$ for EFBMF acoustic panel represented by all five designs demonstrates that $80 \%$ or more of sound energy are successfully absorbed in the test chamber. Based on the $\alpha_{\mathrm{w}}$ value obtained, $100 \mathrm{MF}$ coir panels has the highest absorption coefficient of 0.90 , followed by $90: 10$ coir panels with 0.85 coefficient and the other three panels (50:50 coir, 100 EFB dust and 80:20 dust) with 0.80 coefficients. With reference to this result, $100 \mathrm{MF}$ coir panel is rated as a class A absorber while the other panels were categorized as the class B absorber.

Class A absorber is material that able to absorb more than $90 \%$ of sound incident while class B absorber is capable to absorb in between $80 \%$ to $85 \%$ of sound incident. Materials that able to absorb more than $80 \%$ of sound incident is considered as very absorptive sound absorption material for building [16]. This research has found that coir panels dominates as a good absorber compared to dust panel. Of it, mesocarp coir panel is the most absorbing panel compare to the others. 
Table 1. Rating of sound absorption for EFBMF acoustic panels according to ISO 11654 :1997

\begin{tabular}{|c|c|c|c|c|c|c|c|c|}
\hline $\begin{array}{c}\text { Frequency } \\
(\mathrm{Hz})\end{array}$ & 250 & 500 & $1 \mathrm{k}$ & $2 \mathrm{k}$ & $4 \mathrm{k}$ & $\alpha_{\mathrm{pi}}$ & $\begin{array}{c}\alpha_{\mathrm{w}} \text { (with shape } \\
\text { indicator) }\end{array}$ & Rating Class \\
\hline 100 MF coir & 0.70 & 0.90 & 0.90 & 0.90 & 0.80 & 0.85 & 0.90 & $\mathrm{~A}$ \\
\hline $90: 10$ coir & 0.65 & 0.85 & 0.85 & 0.85 & 0.75 & 0.80 & 0.85 & $\mathrm{~B}$ \\
\hline 100 EFB dust & 0.60 & 0.80 & 0.80 & 0.80 & 0.70 & 0.75 & 0.80 & $\mathrm{~B}$ \\
\hline $80: 20$ dust & 0.60 & 0.80 & 0.80 & 0.80 & 0.70 & 0.75 & 0.80 & $\mathrm{~B}$ \\
\hline $50: 50$ coir & 0.60 & 0.80 & 0.80 & 0.80 & 0.70 & 0.75 & 0.80 & $\mathrm{~B}$ \\
\hline
\end{tabular}

\section{Conclusions}

This research has successfully utilized EFB and MF as a sound absorber for building acoustic use. Findings from this research evidance that $\mathrm{EFB}, \mathrm{MF}$ and mixture of both fibers are comparable to be use as the raw fiber replacing the conventional synthetic sound absorber in the market. Utilizing natural fibers as a new material for building acoustic enable to promotes sustainablity approach in material development for construction.

Authors would like to express special acknowledgement to the Ministry of Higher Education Malaysia (MoHE) for providing the scholarship for this study and to the Faculty of Civil and Environmental Engineering, the Faculty of Architecture, Planning and Surveying, Universiti Teknologi MARA, Shah Alam for providing the technical support and facilities, without which this study would have not been possible. This research represent a part of the main objective of the $1^{\text {st }}$ author's doctorate study

\section{References}

1. BS EN ISO 354 Acoustic Measurement of sound absorption in a reverberation room. (2003)

2. Hughes, W. O., Mcnelis, A. M., Nottoli, C., and Wolfram, E. 29th Aerospace Testing Seminar (2015).

3. BS EN ISO 266 Acoustic-Preferred frequencies. (1997)

4. BS EN ISO 11654 Acoustic -Sound absorbers for use in building-Rating of sound absorption. (1997)
5. Egan, M. D. Architectural Acoustics. p 43, (1988).

6. Abdullah, N., and Sulaiman, F. Biomass Now Sustainable Growth and Use, 75-100, (2013).

7. Murphy, D. J. Journal of Oil Palm Research, 26(MAR), 1-24, (2014).

8. Basri Wahid, M., Abdullah, S. N. A., and Henson, I. E. Plant Production Science, 8(3), 288-297, (2005).

9. Jahaan, F., Aanifah, M., Yee, P. L. A. I., and Wasoh, H. Journal of Oil Palm Research, 26(4), 321-331, (2014).

10. Kadir, A. A., Mohd Zahari, N. A., and Azizi Mardi, N. Advances in Environmental Biology, 7(12), 3826-3834, (2013).

11. Hee, O. K., Putra, A., Nor, M. J. M., Selamat, M. Z. and Ying, L. Z. 23rd International Congress on Sound and Vibration, 1-8, (2016).

12. Latif, H. A., Yahya, M. N., Zaman, I., Sambu, M., Ghazali, M.I and Hatta, N. M. ARPN Journal of Engineering and Applied Sciences, 11, 2462-2466, (2016)

13. Latif, H. A., Yahya, M. N., Rafiq, M. N., Sambu, M., Ghazali, M. I. and Hatta, M. N. M. Applied Mechanics and Materials 773-774, 247-252, (2015).

14. Al Rahman, L., Raja, R. I., Rahman, R. A. and Ibrahim, Z. Research Journal of Applied Sciences, Engineering and Technology, 7(8), 1656-1661 (2014).

15. Ramli, R., Shaler, S., and Jamaludin, M. A. Journal of Oil Palm Research, 14(2), 34-40, (2002).

16. Cavanaugh, W. J. and Wikes, J. A. Architectural Acoustics: Principles and Practice, p59, 1999. 